\title{
Passivation Behavior of Steel Rod and Wires of Nepal in Acidic and Alkaline Solutions
}

\author{
Jagadeesh Bhattarai \\ Central Department of Chemistry, Tribhuvan University \\ GPO Box 2040, Kathmandu, Nepal \\ e-mail:bhattarai_05@yahoo.com.
}

\begin{abstract}
The passivation behavior of steel rods and wires those are produced in Nepal was studied in $1 \mathrm{M} \mathrm{HCl}$ and $1 \mathrm{M} \mathrm{NaOH}$ solutions at $25^{\circ} \mathrm{C}$, open to air using immersion tests and electrochemical measurements. The corrosion resistance of all the examined steel rods and wires in this work is found significantly higher in alkaline $1 \mathrm{M} \mathrm{NaOH}$ than in acidic $1 \mathrm{M} \mathrm{HCl}$, mostly due to an ennoblement of the open circuit corrosion potentials of the steels at passive potential regions in $1 \mathrm{M} \mathrm{NaOH}$ solution at $25^{\circ} \mathrm{C}$. The corrosion rate of all the examined steel rods and wires is about in the range of $1-5 \times 10^{1} \mathrm{~mm} / \mathrm{y}$ in acidic $1 \mathrm{M} \mathrm{HCl}$ solution which is nearly three orders of magnitude lower corrosion resistance than in alkaline $1 \mathrm{M} \mathrm{NaOH}$ solution at $25^{\circ} \mathrm{C}$. Therefore, these steel rods and wires seem to be very corrosion resistance materials in very alkaline environments like a reinforcing concrete.
\end{abstract}

Key words: steels, corrosion rate, open circuit potential, immersion test, electrochemical measurements.

\section{Introduction}

Corrosion causes damage to several steel-structures around the word. Environmental corrosion damage of steels is becoming a big problem since the beginning of $20^{\text {th }}$ century because, steels have been successfully used as structural materials and now it is one of the major construction materials (Uhlig \& Revie 1991). We have a large number of commercial buildings, domestic dwellings, marine structures, bridges, etc, some of which are beginning to show signs of corrosion damages and over the years a large quantity of steels have been used. If the on-going corrosion activity on steel is not addressed, section loss of the structures will occur and significant repair or replacement may eventually be required. Therefore, as time goes on we will have to face new corrosion problems of the steel-structures in different environments.

In this context, corrosionists are recently focused to find out better quality models for the progression of steel corrosion with time. Good control of corrosion of structural materials like steels requires the awareness and co-operation of the entire design team, including engineers and corrosionists. Adequate means for collecting, reporting and recording corrosion information from operational situations must be planned. Furthermore, in order to ensure more durability of the new steel-structures, we need to understand what can be done to ensure that the corrosion risk of the steel should be reduced to a minimum in different environments. In general, the degree of corrosion resistance of steels by atmospheric exposure depends on the environments; the most harmful factors are oxidizing acids and chloride ions, and the most beneficial medium is alkaline. Steels passivate generally at a $\mathrm{pH}$ higher than 10 , eventhough the passivity decreases in very strong alkaline solutions at high temperature in which iron has a tendency to dissolve as ferrous ions $\left(\mathrm{HFeO}_{2}^{-}\right)$ (Uhlig \& Revie 1991). Therefore, alkaline solutions employed in many chemical processing industries have been handled in steel equipment.

In the 1970s when instruments for surface analysis became available, many corrosion studies of steels were performed by using surface analysis techniques (Asami et al. 1976, Kamimura \& Stratmann 2001, Shibata 2007, Fujimoto \& Tsuchiya 2007, Yang \& Macdonald 2007). The corrosion behavior of steels has been mainly investigated in inorganic acids (Kivisakk 2003), a strongly oxidizing peracetic acid (Qu et al. 2008), salts (Nagies \& Heusler 1998), alkaline solutions (Newman 1981; Gonzalez et al. 2007) and marine media (Nishikata et al. 1995; Melchers 2003; Reffass et al. 2006; Isaacs et al. 2007). It has been reported that many heterocyclic compounds containing heteroatoms like $\mathrm{N}, \mathrm{O}, \mathrm{S}$, have been proved 
to be effective inhibitors for the corrosion of steels in acid media (Saliyan et al. 2008). But little has been studied about the corrosion of steels produced and used in Nepal (Bhattarai et al. 2007).

In this context, the main aim of the present work is to study the passivation behavior of steel wires and rods of Nepal, those are used as construction materials for a reinforcing concrete, in acidic $1 \mathrm{M} \mathrm{HCl}$ and alkaline $1 \mathrm{M} \mathrm{NaOH}$ solutions at $25^{\circ} \mathrm{C}$, open to air using corrosion tests and electrochemical measurements.

\section{Materials and Methods}

Three different branded steel rods (named as SR-101, SR-102 and SR-103) and wires (named as SW-1, SW-2 and SW-3) produced by various steel and iron companies of Nepal were used in this study. These steels are used mainly for construction purposes and are the most commonly available in the local market. The chemical composition of a steel rod provided by the local steel and iron companies of Nepal has been presented in Table 1 .

Table 1. Chemical composition of steel rods produced in Nepal

\begin{tabular}{llccccc}
\hline Elements & Carbon $(\mathrm{C})$ & Manganese $(\mathrm{Mn})$ & Silicon(Si) & Phosphorus $(\mathrm{P})$ & $\operatorname{Sulfur}(\mathrm{S})$ & $\operatorname{Iron}(\mathrm{Fe})$ \\
\hline Average weight $(\%)$ & $0.17-0.25$ & 0.90 & 0.40 & 0.05 & 0.05 & balance \\
\hline
\end{tabular}

Prior to the immersion tests and electrochemical measurements, the steel specimens were mechanically polished with a silicon carbide paper No. 600 to 1500 in cyclohexane, degreased by acetone and dried in air. The corrosion rate of the steel wire and rod specimens was estimated from the weight loss after immersion for $240 \mathrm{~h}$ in $100 \mathrm{ml}$ of $1 \mathrm{M} \mathrm{HCl}$ and $1 \mathrm{M} \mathrm{NaOH}$ solutions at $25^{\circ} \mathrm{C}$, open to air. The weight loss measurement was done two times or more for each specimen and the average corrosion rate of individual steel specimens were estimated. The time dependence of the corrosion loss of the steel wire was also estimated at various time intervals.

The open circuit corrosion potentials (OCCP) of the steel wire and rod specimens were measured after immersion for 72 and $2 \mathrm{~h}$, respectively, in acidic $1 \mathrm{M}$ $\mathrm{HCl}$ and alkaline $1 \mathrm{M} \mathrm{NaOH}$ solutions at $25^{\circ} \mathrm{C}$, open to air. The cathodic and anodic potentiostatic polarization measurements were also carried on the steel wires of Nepal in $1 \mathrm{M} \mathrm{NaOH}$ solution at $25^{\circ} \mathrm{C}$. A platinum mesh and saturated calomel electrode were used as counter and reference electrodes respectively. The steel wire and rod specimens were used as working electrodes. All the potentials given in this paper are relative to saturated calomel electrode (SCE).

\section{Results and Discussion}

Figures 1 and 2 showed the corrosion rates of three steel rods and wires after immersion for 190 and 240 hours in acidic $1 \mathrm{M} \mathrm{HCl}$ solution at $25^{\circ} \mathrm{C}$ respectively. The corrosion rates of all the examined steel rods and wires were in the ranges of about 1.3-3.4 $\times 10^{1} \mathrm{~mm} / \mathrm{y}$ and 2-5 $\times 10^{1}$ respectively. Steel rod samples SR-101 and SR-102 showed the corrosion rates in the range of about 1.3-1.7 $\times 10^{1} \mathrm{~mm} / \mathrm{y}$ which were nearly half of the corrosion rate of the SR-103 sample (that is about $3.4 x$ $10^{1} \mathrm{~mm} / \mathrm{y}$ ) in $1 \mathrm{M} \mathrm{HCl}$ solution. Similar trend of the corrosion-resistant behavior of the steel wires of various steel and iron companies of Nepal was clearly observed in $1 \mathrm{M} \mathrm{HCl}$ solution also. Among three different steel wires of Nepal, samples SW-1 and SW-2 showed the corrosion rates in the range of about 2.0-2.5 $\times 10^{1} \mathrm{~mm} /$ $y$ which were nearly half of the corrosion rate of the SW-3 sample. The corrosion rate of the SW-3 was about $5 \times 10^{1} \mathrm{~mm} / \mathrm{y}$ in $1 \mathrm{M} \mathrm{HCl}$ solution. Consequently, both steel rods and wires produced by companies 1 and 2 showed slightly higher corrosion resistance than that of the steels produced by company 3 in acidic solutions. 


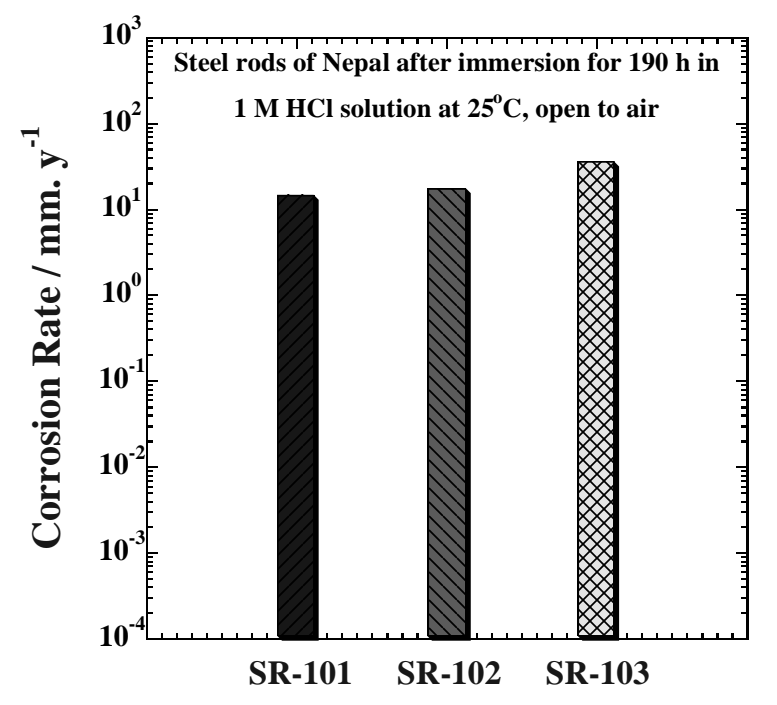

Fig. 1. Corrosion rates of steel rods of Nepal after immersion for $190 \mathrm{~h}$ in $1 \mathrm{M} \mathrm{HCl}$ solution at $25^{\circ} \mathrm{C}$

Figures 3 and 4 showed the corrosion rates of the steel wires and rods respectively, after immersion for 10 days in alkaline $1 \mathrm{M} \mathrm{NaOH}$ solution at $25^{\circ} \mathrm{C}$, open to air. The corrosion rate of the steel rod samples SR-101 and SR-102 was about $2 \times 10^{-3} \mathrm{~mm} / \mathrm{y}$ which was more than one order of magnitude lower than that of the corrosion rate of the steel rod sample SR-103 (that is, about $3 x$ $10^{-2} \mathrm{~mm} / \mathrm{y}$ ). On the other hand, the steel wire samples

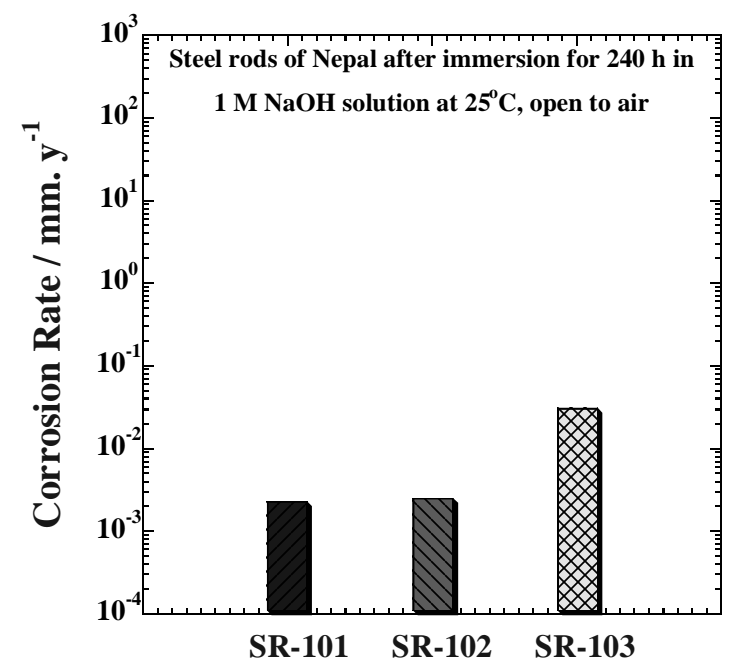

Fig. 3. Corrosion rates of steel rods of Nepal after immersion for 240 hours in $1 \mathrm{M} \mathrm{NaOH}$ solution at $25^{\circ} \mathrm{C}$

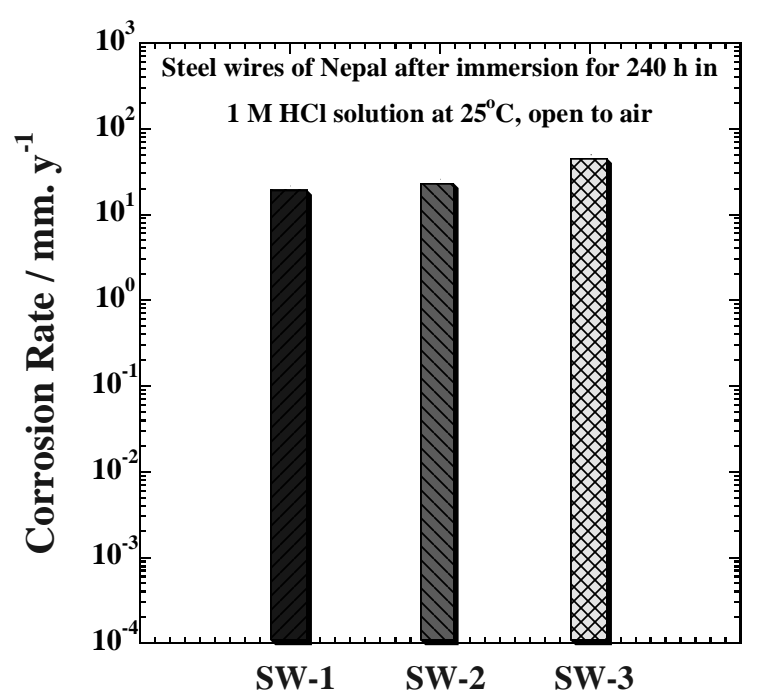

Fig. 2. Corrosion rates of steel wires of Nepal after immersion for $240 \mathrm{~h}$ in $1 \mathrm{M} \mathrm{HCl}$ solution at $25^{\circ} \mathrm{C}$

SW-1 and SW-2 showed almost the same corrosion rates of about $8.0 \times 10^{-3} \mathrm{~mm} / \mathrm{y}$. However, the corrosion rate of the sample SW-3 was about two times (that is, $18.4 x$ $10^{-3} \mathrm{~mm} / \mathrm{y}$ ) than those of SW-1 and SW-2 samples. Consequently, all the examined steel wires and rods of different companies of Nepal showed very high corrosion resistance in $1 \mathrm{M} \mathrm{NaOH}$ solution at $25^{\circ} \mathrm{C}$, open to air.

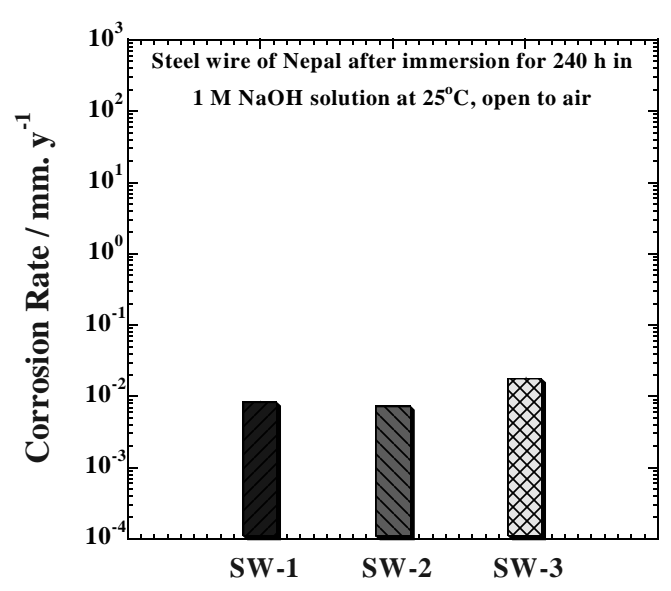

Fig. 4. Corrosion rates of steel wires of Nepal after immersion for $240 \mathrm{~h}$ in $1 \mathrm{M} \mathrm{NaOH}$ solution at $25^{\circ} \mathrm{C}$ 
In order to clarify the time dependence of the corrosion rate of the steels, the corrosion rate of the steel wire samples were estimated after immersion for various time intervals. Figure 5 showed the changes in corrosion rates of the steel wires in acidic $1 \mathrm{M} \mathrm{HCl}$ and alkaline $1 \mathrm{M} \mathrm{NaOH}$ solutions at $25^{\circ} \mathrm{C}$, as a function of immersion time. The corrosion rates of the steel wires were generally high at initial period of immersion (that is, 2 hours) in both acidic and alkaline solutions. However, the corrosion rates of the steel wires become almost steady after immersion for about $35 \mathrm{~h}$ in $1 \mathrm{M} \mathrm{NaOH}$ while the corrosion rates of the wires in $1 \mathrm{M} \mathrm{HCl}$ become almost steady after immersion for about 120 hours. These results revealed that initially faster dissolution of the steel wires of Nepal resulted in faster passivation by forming a more protective passive film on the surface of the steel wire in alkaline $1 \mathrm{M} \mathrm{NaOH}$ solution. Consequently, all the examined steel wires showed very high corrosion resistance in $1 \mathrm{M} \mathrm{NaOH}$ solution at $25^{\circ} \mathrm{C}$, open to air.

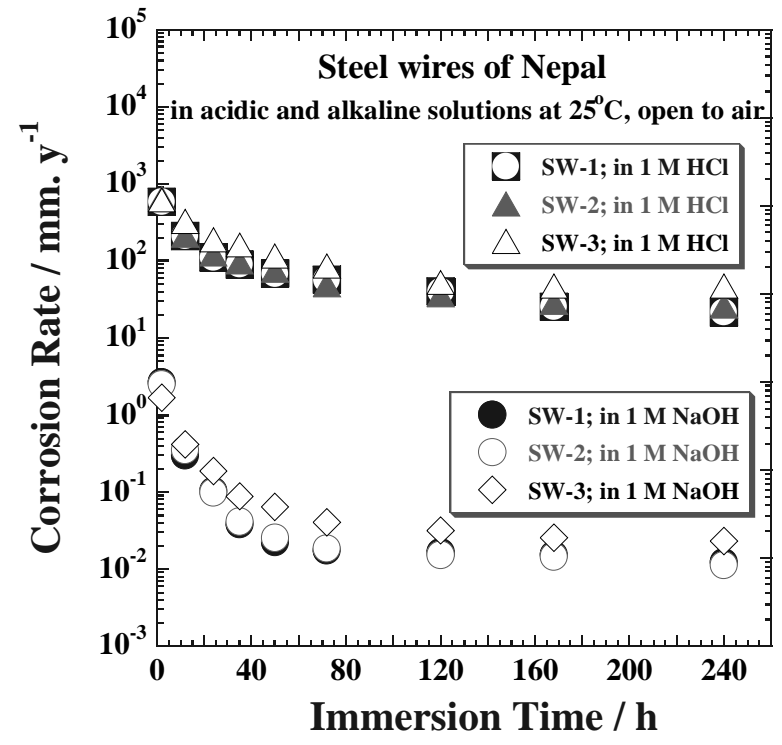

Fig. 5. Changes in corrosion rates of steel wires of Nepal in acidic $1 \mathrm{M} \mathrm{HCl}$ and alkaline $1 \mathrm{M} \mathrm{NaOH}$ solutions at $25^{\circ} \mathrm{C}$, as a function of immersion time
Electrochemical measurements were carried out for a better understanding of the passivation behavior of the steel wire and rod of Nepal after immersion for 72 and $2 \mathrm{~h}$ respectively, in both acidic $1 \mathrm{M} \mathrm{HCl}$ and alkaline $1 \mathrm{M} \mathrm{NaOH}$ solutions at $25^{\circ} \mathrm{C}$, open to air. Figure 6 shows the changes in open circuit corrosion potentials of the steel rod and steel wire samples in $1 \mathrm{M}$ $\mathrm{HCl}$ solution, as a function of immersion time. The changes in the open circuit potentials for the examined steel wires and rods are not significant with immersion time. The open circuit potentials of all the examined steel wires are more negative value (that is, in the range of about -500 to $-535 \mathrm{mV}, \mathrm{SCE}$ ) than those of steel rods (that is in the range of -425 to $-435 \mathrm{mV}, \mathrm{SCE}$ ) after $2 \mathrm{~h}$ immersion in $1 \mathrm{M} \mathrm{HCl}$, and hence steel rods showed more passivity and corrosion-resistant than those of steel wires. However, the open circuit potentials of the steel wires shifted to more positive potential range (i.e., about -512 to $-464 \mathrm{mV}, \mathrm{SCE})$ after 72 hours immersion. These facts coincide with the changes in the corrosion rates of the steel rod and wire samples in $1 \mathrm{M} \mathrm{HCl}$ solution as shown in Figures 1 and 2.

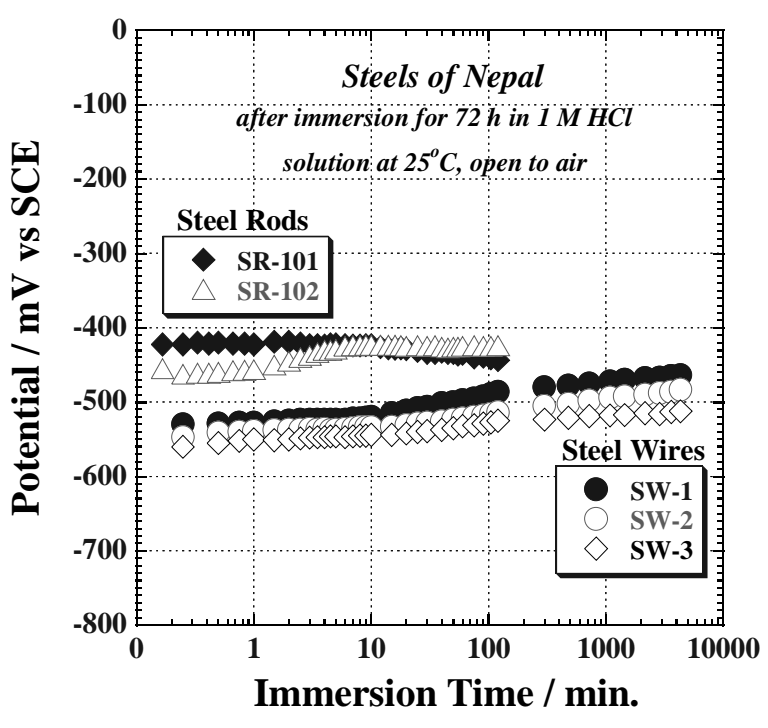

Fig. 6. Changes in open circuit corrosion potentials of steel rods and wires of Nepal in acidic $1 \mathrm{M} \mathrm{HCl}$ solution at $25^{\circ} \mathrm{C}$, as a function of immersion time 
On the other hand, the nature of change of the open circuit corrosion potentials of the steel wire and rod samples with immersion time in alkaline $1 \mathrm{M} \mathrm{NaOH}$ solution was not same as in acidic $1 \mathrm{M} \mathrm{HCl}$ solution. The changes in the open circuit potentials for all the examined steel rod and wire samples are shown in Figure 7 in $1 \mathrm{M} \mathrm{NaOH}$ solution at $25^{\circ} \mathrm{C}$, as a function of immersion time. The changes in the open circuit potentials for all the examined steel rods and wires were clearly observed with immersion time and shifted to more positive (or more noble) direction in alkaline $1 \mathrm{M}$ $\mathrm{NaOH}$ solution. The open circuit potentials of all the examined steel rods are more positive value (that is, in the range of about -140 to $-160 \mathrm{mV}, \mathrm{SCE}$ ) than those of steel wires (that is, in the range of -280 to $-300 \mathrm{mV}$, $\mathrm{SCE}$ ) after immersion for $2 \mathrm{~h}$ in $1 \mathrm{M} \mathrm{NaOH}$, and hence steel rods showed more passivity and corrosion-resistant than those of steel wires as shown in Figures 3 and 4. However, the open circuit potentials of the steel wires shifted to more positive potential range (i.e., about 204 to $-160 \mathrm{mV}, \mathrm{SCE}$ ) after immersion for $72 \mathrm{~h}$ in alkaline $1 \mathrm{M} \mathrm{NaOH}$ solution. Consequently, steel rods and wires were more passive in alkaline $1 \mathrm{M} \mathrm{NaOH}$ than that in acidic $1 \mathrm{M} \mathrm{HCl}$. These facts coincide with

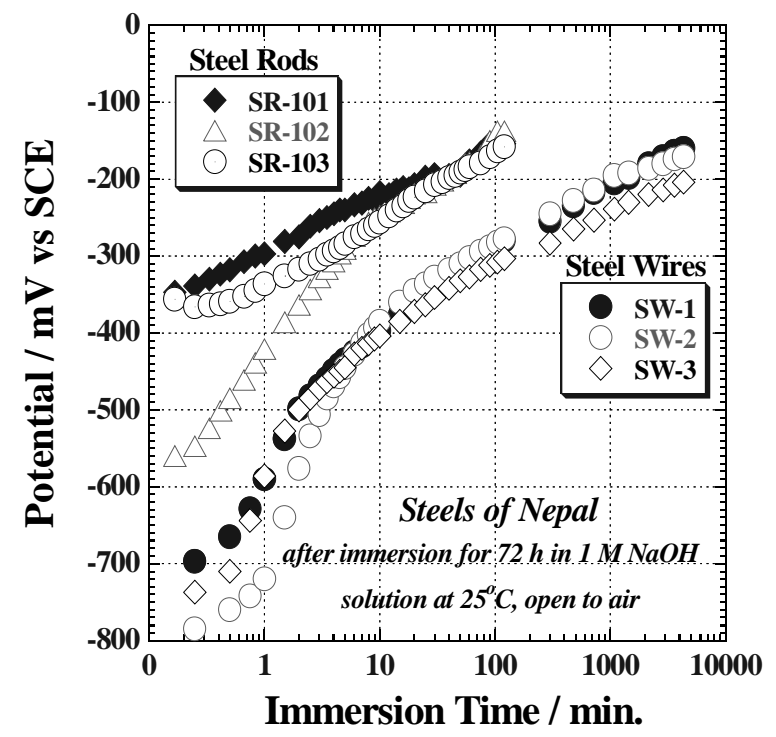

Fig. 7. Changes in open circuit corrosion potentials of steel rods and wires of Nepal in alkaline $1 \mathrm{M} \mathrm{NaOH}$ solution at $25^{\circ} \mathrm{C}$, as a function of immersion time the changes in the corrosion rates of the steel wires in both $\mathrm{HCl}$ and $\mathrm{NaOH}$ solutions as shown in Figures 1, 2, 3 and 4 .

Figure 8 showed the potentiostatic anodic and cathodic polarization curves for the steel wires after polarization for $1 \mathrm{~h}$ in alkaline $1 \mathrm{M} \mathrm{NaOH}$ solution at $25^{\circ} \mathrm{C}$, open to air. All the examined steel wires show clearly the active-passive transition and transpassivation. The steel wire is active at the potential range between -500 to $-250 \mathrm{mV}$ (SCE) while it is passive at the potential range between -200 to $250 \mathrm{mV}$ (SCE) in $1 \mathrm{M} \mathrm{NaOH}$ solution. The passive current density of the steel wires was in the range of 2-4 $\times 10^{-2} \mathrm{~A} / \mathrm{m}^{2}$ in 1 $\mathrm{M} \mathrm{NaOH}$ solution. Transpassivity was clearly seen after polarization at about $200 \mathrm{mV}$ (SCE) or more anodic potentials probably due to the formation of soluble ferrate $\left(\mathrm{FeO}_{4}^{2-}\right)$ in $1 \mathrm{M} \mathrm{NaOH}$ solution (Uhlig \& Revie 1991). Consequently, the corrosion rates of the steel wires and rods are significantly higher in $1 \mathrm{M} \mathrm{HCl}$ than those in $1 \mathrm{M} \mathrm{NaOH}$ as shown in Figures 1, 2, 3, 4 and 5. This is mostly due to an ennoblement of the open circuit potentials of steel wires at passive potential regions in $1 \mathrm{M} \mathrm{NaOH}$ solution at $25^{\circ} \mathrm{C}$.

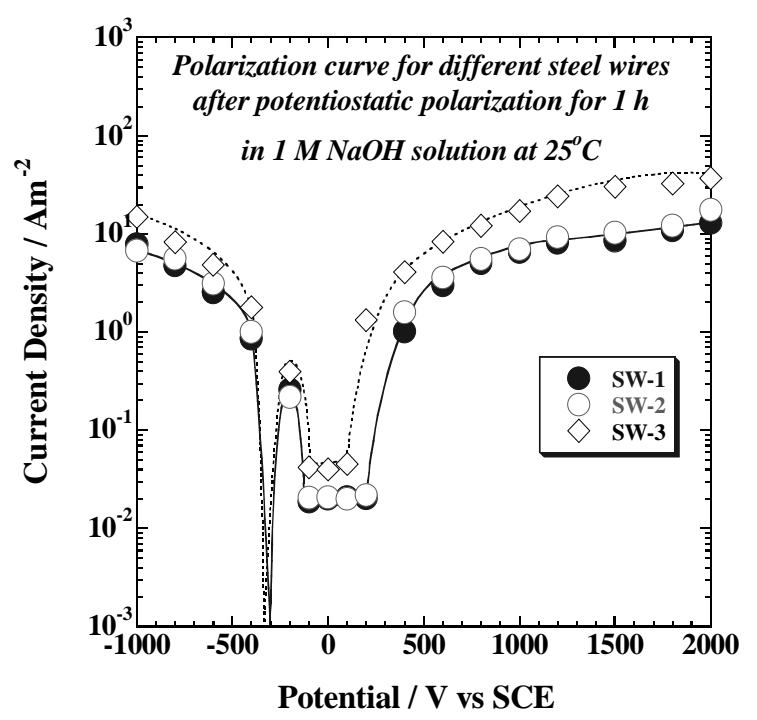

Fig. 8. Potentiostatic polarization curves of the steel wires of Nepal in $1 \mathrm{M} \mathrm{NaOH}$ solution at $25^{\circ} \mathrm{C}$, open to air 
The steel rods and wires produced by companies 1 (samples SR-101 \& SW-1) and 2 (samples SR-102 \& SW-2) showed higher corrosion resistance than that of the steels produced by company 3 (samples SR-103 \& SW-3) in both acidic and alkaline solutions.

The corrosion resistance of all examined steel rods and wires of Nepal is significantly higher in alkaline solutions than in strong acidic solutions, mostly due to an ennoblement of the open circuit potentials of steels at passive potential regions of steel in $1 \mathrm{M} \mathrm{NaOH}$, while OCPs of the steels were located in the active potential regions in acidic $1 \mathrm{M} \mathrm{HCl}$ solution at $25^{\circ} \mathrm{C}$.

The faster dissolution of the steels of Nepal results in faster passivation by forming a more protective passive film on the surface of the steels in alkaline 1 $\mathrm{M} \mathrm{NaOH}$ solution. Therefore, these steel rods and wires seem to be very corrosion resistance in very alkaline environments like of the reinforced concrete.

\section{Acknowledgement}

The author is very thankful to the Head of Central Department of Chemistry, Tribhuvan University, Kirtipur, Kathmandu, Nepal for providing the available research facilities to conduct this research. An appreciation goes to Professor Lalanath Subedi, Asstt. Dean, Institute of Engineering, Tribhuvan University, Lalitpur for providing facilities of the edge cutting machine.

\section{References}

Asami, K., K. Hashimoto and S. Simodaira. 1976. X-ray photoelectron spectrum of $\mathrm{Fe}^{2+}$ state in iron oxides. Corrosion Science 16: 35-45.

Bhattarai, J., A. Kafle and N. P. Bhattarai. 2007.The passivation behavior of carbon steel rods of Nepal in different media. Journal of Nepal Chemical Society 22: $34-40$.
Fujimoto, S. and H. Tsuchiya. 2007. Semiconductor properties and protective role of passive films of iron base alloys. Corrosion Science 49: 195-202.

Gonzalez, J. A., J. M. Miranda, E. Otero and S. Felius. 2007. Effects of electrochemically reactive rust layers on the corrosion of steel in a $\mathrm{Ca}(\mathrm{OH})_{2}$ solution. Corrosion Science 49: 436-448.

Isaacs, H. S., Y. M. Looi and J. H. W. de Wit. 2007. Behavior of laser welded steel in chloride solution studied using different imaging. Corrosion Science 49: 53-62.

Kamimura, T. and M. Stratmann. 2001. The influence of chromium on the atmospheric corrosion of steel. Corrosion Science 43: 429-447.

Kivisakk, U. 2003. Corrosion behavior of steel in inorganic acids. Corrosion Science 45: 485-491.

Melchers, R. E. 2003.The degradation of steels in marine environment. Corrosion Science 45: 2609.

Nagies, F. and K. E. Heusler. 1998. Passivity of steel in different salts. Electrochimica Acta 43: 41-47.

Newman, J. E. 1981. The stress corrosion of steel in sodium hydroxide solution: a film-ruptured model. Corrosion Science 21: 487-503.

Nishikata, A., Y. Yamashita, H. Katayama, T. Tsuru, A. Usami, K. Tanabe and H. Mabuchi. 1995. An electrochemical impedence study on atmospheric corrosion of steels in a cyclic wet-dry condition. Corrosion Science 37: 2059-2069.

Qu, Q., S. Jiang, L. Li, W. Bai and J. Zhou. 2008. The passivation behavior of carbon steel in peracetic acid. Corrosion Science 50: 35-40.

Reffass, M., R. Sabot, C. Savall, M, Jeannin, J. Creus and $\mathrm{Ph}$. Refait. 2006. Localized corrosion of carbon steel in $\mathrm{NaHCO}_{3} / \mathrm{NaCl}$ electrolytes. Corrosion Science $\mathbf{4 8}$ : 709-726.

Saliyan, V. R. and A. V. Adhikari. 2008. Effects of different inhibitors for corrosion study of steel in acidic media. Corrosion Science 50: 55-61.

Shibata, T. 2007. Passivity breakdown and stress corrosion craking of stainless steel. Corrosion Science 49: 20-30.

Uhlig, H. H. and R. W. Revie. 1991. Corrosion and corrosion control ( $3^{\text {rd }}$ edition). Wiley-Interscience Publication.

Yang, S. and D. D. Macdonald. 2007. Theoretical and experimental studies of the pitting of type 316L stainless steel. Electrochimica Acta 52: 1871-1879. 